\title{
Recent advances in rotavirus reverse genetics and its utilization in basic research and vaccine development
}

\author{
Tirth Uprety ${ }^{1} \cdot$ Dan Wang ${ }^{1} \cdot$ Feng Li $^{1}$ (i)
}

Received: 28 February 2021 / Accepted: 27 April 2021 / Published online: 3 July 2021

(C) The Author(s), under exclusive licence to Springer-Verlag GmbH Austria, part of Springer Nature 2021

\begin{abstract}
Rotaviruses are segmented double-stranded RNA viruses with a high frequency of gene reassortment, and they are a leading cause of global diarrheal deaths in children less than 5 years old. Two-thirds of rotavirus-associated deaths occur in low-income countries. Currently, the available vaccines in developing countries have lower efficacy in children than those in developed countries. Due to added safety concerns and the high cost of current vaccines, there is a need to develop costeffective next-generation vaccines with improved safety and efficacy. The reverse genetics system (RGS) is a powerful tool for investigating viral protein functions and developing novel vaccines. Recently, an entirely plasmid-based RGS has been developed for several rotaviruses, and this technological advancement has significantly facilitated novel rotavirus research. Here, we review the recently developed RGS platform and discuss its application in studying infection biology, gene reassortment, and development of vaccines against rotavirus disease.
\end{abstract}

\section{Introduction}

Rotaviruses (RVs) form a genus in the family Reoviridae, which is divided into two subfamilies: Sedoreovirinae and Spinareovirinae. The subfamily Sedoreovirinae has six genera, with Rotavirus as one of them. Rotaviruses were originally identified in mice and in vervet monkeys [1,2], and later in humans $[3,4] . \mathrm{RV}$ is a double-stranded RNA virus with 11 genome segments encoding six structural proteins (VP) and six non-structural proteins (NSP). Segments 1, 2, 3 , and 4 code for VP1, VP2, VP3, and VP4, respectively. VP4 is proteolytically cleaved into VP5* and VP8* during viral replication. Segments 6 and 9 encode VP6 and VP7. Segment 5 encodes NSP1, while segments 7, 8, and 10 code for NSP3, NSP2, and NSP4. Segment 11 has two open reading frames that express NSP5 and NSP6, respectively. The genome segments of rotavirus are numbered according to their migration pattern in analytical gels, which can be strain-specific. For example, segment 3 in RVD strain

Handling Editor: Reimar Johne

Feng Li

Feng.Li@uky.edu

1 Department of Veterinary Science, M. H. Gluck Equine Research Center, University of Kentucky, Lexington, KY 40546, USA
Ch-49 encodes VP4, while segment 9 in group A rotavirus (RVA) strain Ch-2G3 encodes NSP2 [5]. The total genome size is approximately $18.5 \mathrm{~kb}$ with individual genome segment sizes ranging from 667 to 3302 bp in length. The RV virion structure is presented diagrammatically in Figure 1. The genus Rotavirus has nine species, also called groups or serogroups, designated as A-D and F-J [6]. The demarcation of these groups is based on nucleotide (nt) sequence differences in the gene encoding the inner capsid protein VP6 [7]. Rotaviruses belonging to groups $\mathrm{A}, \mathrm{B}, \mathrm{C}$, and $\mathrm{H}$ can infect humans and animals, while those belonging to groups $\mathrm{D}, \mathrm{F}$, and $\mathrm{G}$ predominantly infect animals [8]. Zoonotic transmission of animal RVs, such as those from group A, to humans has been observed in the field, and these animal RVs can cause diarrhea in humans $[9,10]$.

RVAs are of clinical importance as they are a leading cause of acute severe gastroenteritis and life-threatening diarrhea in infants and children worldwide. In addition to causing a similar spectrum of diseases in infants and children, group B and C rotaviruses (RVB and RVC) can also infect adults [11-13]. A study conducted during the 1980s in China showed that an RVB strain caused clinical diarrhea in some adults $[14,15]$. RVs are also a health concern for elderly and immunocompromised adults, although the disease is often less severe. Globally, RVs are the primary cause of death due to diarrhea in children under the age of five [16]. Based on serological assays and the nucleotide 


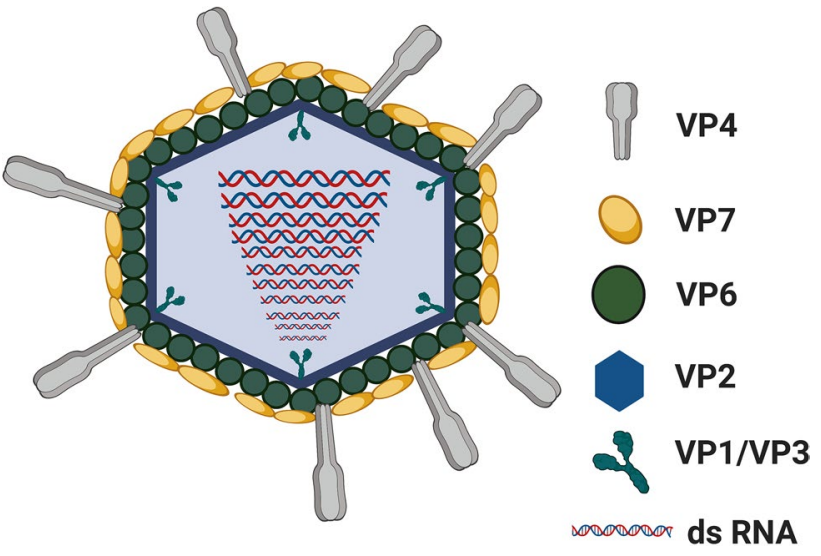

Fig. 1 Schematic representation of rotavirus structure. The infectious virion (TLP) has three layers of capsid protein. The innermost core protein VP2 forms an icosahedron with 125 -fold hubs projecting into the DLP layer. The replication complexes, consisting of VP1 and VP3, are located on the inside of the hubs. Each replication complex is linked to a dedicated dsRNA segment, coiled inside the core. The middle capsid layer protein VP6 is the most conserved and is the basis for demarcation of rotaviruses into different groups. The outermost layer is composed of VP7 glycoprotein with VP4 spike proteins submerged in it. The VP4 spike protein is cleaved by a protease into two subunits, VP5* and VP8*.

sequences of the two outer capsid protein sequences, two major serotypes/genotypes of RVA are identified, the G serotype (based on the VP7 sequence) and the P serotype (based on the VP4 sequence), and this is the foundation of a dual classification system that has been utilized internationally for serotyping RVs. For P serotypes, nucleotide sequences are usually used, since there are not sufficient numbers of $\mathrm{P}$ type-specific antisera available. Currently, there are $36 \mathrm{G}$ serotypes and $51 \mathrm{P}$ genotypes $[17,18]$. G1-G4, G9, G12, P[8], and P[4] are the predominant G and $\mathrm{P}$ serotypes that are involved in more than $90 \%$ of all human RV infections [19-21]. The complete genome sequence has been used to establish the most recent RVA classification system, which is based on percent nucleotide sequence identity calculations. Cutoff values are used for each segment, and a new genotype is established if the percent nucleotide sequence identity value is below the cutoff [22]. In the new nomenclature system, Gx-P[x]-IxRx-Cx-Mx-Ax-Nx-Tx-Ex-Hx designates the VP7, VP4, VP6, VP1, VP2, VP3, NSP1, NSP2, NSP3, NSP4, and NSP5/6 genotype, respectively [23-25]. There are three major genomic constellations (Wa-like, DS-1-like, and AU-1-like) of RVA circulating in humans. These genomic constellations are based on the complete genome sequence similarities, excluding $\mathrm{P}$ and $\mathrm{G}$ genome sequences. The Wa-like constellation has an ancestor in common with porcine RVA, while the DS-1-like constellation has an ancestor in common with bovine RVA [22]. These are the two major RVA constellations circulating in humans. The less-common AU-1-like constellation has an ancestor in common with dog and cat rotaviruses [26].

The traditional method for studying gene functions relies on introducing mutations into the DNA sequence of an organism, selecting organisms with the desired phenotype, and then probing its genotype by comparison with the wildtype organism. This method, termed 'forward genetics' is tedious and cumbersome. With advancements in genome sequencing along with more-precise gene editing technologies, the 'reverse genetics' system (RGS) has emerged as a robust platform for studying gene functions. In the RGS, mutations are introduced into the DNA sequence of the target gene. The organism is then studied for phenotypic changes, and the genotype and phenotype can be precisely correlated [27]. In virology, RGSs have been used to generate replication-competent viruses from plasmid DNA or cDNA. RGS development is generally easier for DNA viruses than for RNA viruses because viral DNA genomes are often infectious upon transfection into suitable cell lines. The development of RGSs for segmented dsRNA viruses like RV has proven challenging, as cloning of full-length dsRNA genome-derived cDNA has been difficult in the past several decades, primarily due to the unavailability of sequence information, problems with genome stability, and the need to perform transfections with multiple plasmids [28].

A robust RGS is a powerful tool for studying host-pathogen interactions, viral protein functions, and the infection biology of the virus, including the type of cellular receptor used, replication steps, and attenuation mechanisms. In addition, the RGS can be manipulated in great detail for rational vaccine design [29-31]. Over the past several decades, advances in research on RV infection at the molecular level and vaccine development have been significantly hampered by the lack of an efficient RGS. After an investment of great effort, this barrier has recently been eliminated by several reports describing the development of successful RGSs for several rotaviruses. Here, we review some recent progress and discuss the potential and limitations of these systems for advancing molecular biology research and development of rotavirus vaccines.

\section{Rotavirus non-coding regions}

There are 11 separate segments comprising the dsRNA genome of a rotavirus. Specifically, segments 1-10 each code for a single protein, while segment 11 encodes two proteins, as it contains two initiation codons located in different reading frames [32]. Each open-reading frame (ORF) has 5' and 3' untranslated regions (UTRs). Table 1 shows the 5' and 3' UTR sequences for all 11 segments of a group A rotavirus (RVA/Simian-tc/ZAF/SA11-H96/1958/ 
Table 1 Nucleotide sequences of the 5' and 3' untranslated regions of simian rotavirus SA11*

\begin{tabular}{lll}
\hline $\begin{array}{l}\text { Genome seg- } \\
\text { ment }\end{array}$ & $\begin{array}{l}\text { 5' UTR sequence } \\
\text { (first 10 nucleotides) }\end{array}$ & $\begin{array}{l}\text { 3' UTR sequence } \\
\text { (last 10 nucleotides) }\end{array}$ \\
\hline 1 & GGCUAUUAAA & AGAUGUGACC \\
2 & GGCUAUUAAA & AGAUAUGACC \\
3 & GGCUUUUAAA & UGAUGUGACC \\
4 & GGCUAUAAAA & GGAUGUGACC \\
5 & GGCUUUUUUU & ACUGUGAACC \\
6 & GGCUUUUAAA & GGAUGUGACC \\
7 & GGCAUUUAAU & UUAUGUGGCC \\
8 & GGCUUUUAAA & UUAUGUGACC \\
9 & GGCUUUAAAA & UGAUGUGACC \\
10 & GGCUUUUAAA & UAAUGUGACC \\
11 & GGCUUUUAAA & UUUUGUGACC \\
\hline
\end{tabular}

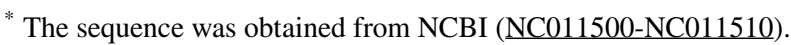

G3P5B). Each positive-sense strand has a 5' cap but lacks a 3 ' poly(A) tail $[33,34]$. The terminal non-coding ends of all 11 segments are variable in their sequence but exhibit a high degree of sequence similarity within the first 10 nucleotides at either end. The sequence conservation is relatively high among homologous segments of different rotavirus strains within the same group, but it is low between groups [35, 36]. Numerous studies have demonstrated that the terminal ends of each segment contain packaging signals that are required for incorporation of the segmented genome into budding virions during virus replication. The lack of RGSs and in vitro assays over the past few decades has hindered progress on identifying the packaging signals of rotaviruses $[37,38]$.

The 5' and 3' consensus sequences in most cases are 5'-GGC (A/U) $)_{6-8}-3$ ' and 5'-UGUGACC-3', respectively. The 3 ' consensus sequence of groups $\mathrm{A}, \mathrm{C}, \mathrm{D}$, and $\mathrm{F}$ is either 5'-UGUGACC-3' or 5'-UGUGGCU-3', whereas its counterpart of groups B, G, and $\mathrm{H}$ is 5'-AAAACCC-3', 5'-AAG ACCC-3', or 5'-UAUACCC-3' [38, 39]. Interestingly, the 3 ' consensus sequence contains cis-acting signals that are necessary for viral replication [35]. Mutagenesis studies of the 3 ' consensus sequence have shown that $\mathrm{CC}$ nucleotides at the terminal end are essential for initiation of minusstrand synthesis [35]. The final four nucleotides, GACC, at the 3 ' end, termed translation enhancer, have been shown to stimulate protein expression in virus-infected cells [40]. A comparison of the 5'- and 3'-terminal sequences of different groups of RVs are included in Supplementary Table S1 and Supplementary Table S2, respectively. RV exploits the eukaryotic translational machinery to benefit its own replication. In eukaryotes, the mRNA has a 5' cap and 3' poly(A) tail, and protein translation is initiated by the interaction of the 5' and 3' ends after binding of poly(A) binding protein (PABP), which is followed by binding of eukaryotic translation initiation factor $4 \mathrm{G}$ (eIF4G). Recognition of the 5' cap structure by eIF4G is essential for initiation of translation. Intriguingly, RV RNA lacks a 3' poly(A) tail. Recent studies revealed that the poly(A) tail and its associated function have been substituted by a tetranucleotide motif at the 3 ' end, which acts as a translation initiator for RV protein synthesis. The N-terminal region of RV NSP3 (segment 7) binds to the tetranucleotide motif at the 3' end. The C-terminal region of NSP3 has binding domains for the translation initiation factor eIF4G. Thus, binding of the $\mathrm{N}$-terminal region of NSP3 to the 3' tetranucleotide sequence together with the engagement of eIF4G with its $\mathrm{C}$-terminal region facilitates the formation of circularized mRNA molecules ('panhandles', see below), which as a result, triggers initiation of viral protein translation. These data highlight that the 3'-terminal sequence of each segment is essential for the translation of RV proteins [41-46].

The 5'-terminal end starts with the dinucleotide GG, which is present in all segments of the RV dsRNA genome in all genotypes. Mutational analysis has revealed that the GG dinucleotide motif acts as a recognition signal for the RNA-dependent RNA polymerase (RdRp) and its cofactors. This base-specific recognition leads to the formation of an initiation complex, which is necessary for minus strand synthesis [47]. The UTRs at the 5' and 3' ends are believed to undergo complementary base-pairing, which drives the energy-dependent folding of the positive RNA strand into a high-order panhandle structure. In this panhandle structure, the 3 '-terminal sequence is either unpaired or partially basepaired, which makes the 3' terminus of the positive RNA strand accessible to RdRp for subsequent viral RNA genome synthesis [48, 49]. In the T7-polymerase-promoter-driven cDNA reverse transcription system for RV segments, the 5' UTR can have inhibitory effects on viral protein synthesis. For RV strain SA11, such effects were observed for genome segments 3, 5-6, and 7-11. The presence of inhibitory motifs in the 5' UTR of certain genome segments has a negative impact on the rescue efficiency of recombinant RVs. Further investigations have shown that the inhibitory motifs are present in the form of a six-nucleotide-long pyrimidinerich motif (5'-GGY(U/A)UY-3') located at the 5' terminus. Introduction of the nucleotide G upstream of the 5' UTR and replacing $\mathrm{U}$ with $\mathrm{A}$ at the fifth nucleotide position abolished the inhibitory motif, which in turn enabled rescue of infectious RVs in a helper-virus-free RGS [50].

\section{Rotavirus replication}

Infectious RV particles have a triple-layered capsid (TLP) lattice that encases a dsRNA genome containing 11 separate segments. The TLP consists of VP7, VP6, and VP2, which form the outer, middle, and inner layer of the capsid, 
respectively. The outermost spike protein VP4 is embedded within the VP7 layer and interacts deeply with the middle layer VP6 [51-54]. RV infection and replication occur mostly in enterocytes, especially at the tips of villi [55]. Rotaviruses use glycan receptors for attachment and entry into cells. This attachment is mediated by the receptor-binding domain of VP8*, which is derived from the VP4 spike protein through proteolytic cleavage, either by trypsin or another exogenous or cellular protease $[51,56]$. In addition to VP8*, this cleavage event also gives rise to VP5*.

Despite the significant progress made toward understanding RV entry, identification of functional receptors has remained elusive. Recent studies have indicated that some animal RVA strains use sialoglycans as functional receptors for infection. However, it is generally believed that most animal RVAs do not seem to utilize sialic acid-containing glycans for entry, which has also been observed with human RVAs [57]. In addition, the role of histo-blood group antigens (HBGAs) as functional receptors for RV entry is still questionable because the majority of human RVs seem to infect cultured cells independently of HBGAs [58] despite the fact that in vitro binding of HBGAs by human RVAs has been demonstrated in some studies. It is interesting to note that various other coreceptors or cofactors for RV entry have also been proposed, such as integrins, heat shock proteins, and tight junction proteins [59-62] .

After initial attachment, VP4 undergoes a conformational change whereby $\mathrm{VP}^{*}$, hidden beneath the receptor-binding domain of VP8*, is exposed. VP8* binds to the glycan receptor, while VP5* interacts with coreceptors such as integrins and heat shock proteins [63]. Based on the observation that stepwise blocking each of these receptors and coreceptors individually reduced the viral titer but did not completely prevent RV entry and replication, it has been speculated that RVs may utilize a still unidentified receptor that is more important for entry than the previously characterized receptor/coreceptors. Alternatively, it can be envisioned that RV may utilize multiple pathways for cell entry [64], which warrants further investigation. Following receptor binding, RVs can enter a cell by either clathrin-dependent or clathrinindependent endocytosis [65, 66]. Most human and animal RVs use clathrin-dependent endocytic pathways, while simian RVs have been shown to utilize clathrin-independent endocytosis. Interestingly, the clathrin-independent endocytosis used by simian RVs is dependent on the presence of certain molecules on the cell surface, such as dynamin and other small Rho GTPases. It has been suggested that critical amino acid residues or domains of VP8* other than the glycan receptor dictate which endocytic pathway will be utilized by the virus $[64,67]$. Following endocytosis, the $\mathrm{RV}$ virion reaches early endosomes, then late endosomes, and ultimately, mature endosomes. The low concentration of calcium in endosomes results in a complete loss of the outer layer of the TLP, resulting in the formation of a doublelayered particle (DLP), which is transcriptionally active [68].

The mechanism of RV replication and particle assembly are still incompletely understood [36]. Rotavirus ss (+) RNA synthesis occurs in subviral particles. The VP1 (RdRp)-VP3 (RNA capping enzyme) complex is tethered to VP2 (core shell) at the five-fold symmetry axes of the virion [69]. Since a polymerase complex (PC) is needed for the synthesis of each segment, it is unknown how these segment-specific polymerase complexes interact with each other to initiate replication of multiple segments almost simultaneously [70, 71]. The PC gives rise to 5'-capped positive-sense single-stranded RNA transcripts from the negative-sense single-stranded RNA template. (A more-detailed molecular mechanism has been described in reference 71.) These nascent transcripts exit into the cytosol, where they capture components of the cellular translational machinery for the synthesis of viral proteins. The viral proteins NSP2 and NSP5 colocalize near the DLP to form an inclusion body called a viroplasm. A highly packed supramolecular complex composed of 11 positive-sense single-stranded RNAs and VP2, VP1, and VP3 is believed to drive the synthesis and replication of negative-strand RNA [72, 73]. In addition, the transcapsidation of RV cores by VP6, also present in viroplasm, gives rise to DLPs. Upon the completion of RNA genome replication, the nascent subviral particles exit the viroplasm and enter the endoplasmic reticulum (ER), where viral particle maturation takes place. This process is facilitated by interactions between NSP4 and VP6, which is inserted into the ER and acts as an intracellular receptor for DLPs [74]. In the ER, the DLP transiently acquires an envelope, which is then removed by a so far unknown mechanism. The origin and function of transiently enveloped particles remain unknown. The precise mechanism for the physical acquisition of the VP4 protein is also unclear. VP4 is thought to be retained as a heterotrimer (through interaction with VP7 and NSP4) near the viroplasm and ER membrane [75]. VP4 is then internalized in the lumen along with VP7, which catalyzes the viral assembly process, which may occur concomitantly with the removal of the transiently acquired envelope [76]. Since VP4 has been found to interact with lipid rafts after exiting from the ER, it has also been suggested that the final assembly involving VP4 and VP7 may take place after egress from the ER [77, 78]. Historical evidence has suggested that RV particles are released by cell lysis, a mechanism commonly used by non-enveloped viruses [79]. Some earlier studies showed that RV could exit from both non-polarized and polarized cells, indicating that mature virions (TLPs) can get released from infected cells either by cell lysis (mostly observed in non-polarized cells) or by budding (observed in polarized epithelial cells) [76, 80-82]. However, recent work has demonstrated that RVs can also bud from non-polarized cells without obvious cell 
lysis [80-82]. Specifically, these studies revealed that RV hijacks the cellular actin network to promote infectious particle release. The VP4 protein was found to interact with actin filaments of the brush border in intestinal epithelial cells, leading to the formation of actin bodies. The actin bodies are thought to remodel the apical membrane and induce membrane curvature, which subsequently drives the release of rotavirus particles from infected cells [76, 83]. Further study is needed to further clarify the RV egress pathway in order to achieve better understanding of the molecular mechanism that drives the production of infectious RV particles.

\section{Reverse genetics systems (RGSs) for rotaviruses}

Development of a plasmid-only-based RGS for RVs took more effort than previously thought, especially after the development of a successful RGS for orthoreoviruses [84]. The major hindrance associated with the RV plasmid-onlybased RGS was a lack of translation or inefficient translation of transcripts. Both in vitro-synthesized positive-sense RNA transcripts and viral transcripts from $\mathrm{T} 7$ transcription of viral cDNA failed to be efficiently translated when introduced into cells by transfection. Inefficient translation was often associated with cytotoxic effects in transfected cells [85]. In the absence of productive translation, non-structural proteins such as NSP1, which are antagonists of host-mediated antiviral responses, are not made in sufficient amounts to prevent innate immunity from rapidly and profoundly perturbing viral RNA transcription and protein synthesis, thereby decreasing the likelihood of virus rescue. Furthermore, sensing of viral RNA by the host innate immune system could have led to a cytotoxic T cell response, which would decrease virus replication and make the subsequent rescue inefficient [18, 86, 87]. Broadly speaking, an RV RGS system can be divided into helper-virus-dependent RGSs and plasmid-only-based RGSs.

\section{Helper-virus-dependent RGSs}

Prior to the development of an efficient plasmid-only-based RGS for RVs, studying the functions of viral proteins and addressing the mechanism of viral replication depended largely on gene reassortment experiments involving coinfection of the same cells with two parental RV strains. New RV reassortants were selected in a random fashion for further genotype-phenotype studies, which was labor-intensive and time-consuming [88]. In some cases, mono-gene-reassortant viruses were difficult to generate due to the different replication levels of the two parental viruses. To address these limitations and improve efficiency, a single-gene-replacement approach was developed and used to manipulate the genome and interrogate gene functions of RV. In 2006, using helper viruses, the first gene replacement platform for artificial manipulation of RV genome segments was developed [89]. This protocol was based on modifications of an RGS that was developed previously for influenza A virus [90]. Briefly, the PCR-amplified VP4 segment from simian RV strain SA11 was flanked by a T7 RNA polymerase promoter and a hepatitis delta virus (HDV) ribozyme sequence. A T7 RNA polymerase terminator was inserted downstream of the HDV ribozyme sequence. The VP4 plasmid was introduced by transfection into COS-7 cells infected with a recombinant vaccinia virus, where T7 RNA polymerase produced by vaccina virus recombinant recognized and transcribed the plasmid DNA to make the VP4 protein. A day after transfection with the VP4 expression plasmid, COS-7 cells were infected with the RV KU strain, and the culture supernatant was then passaged in MA104 cells in the presence of two neutralizing monoclonal antibodies directed against the VP4 of the wildtype KU helper virus. This led to the successful rescue of a recombinant virus that incorporated the VP4 segment of different RV strains in the backbone of the wild-type helper virus [89]. The use of T7 RNA polymerase had an additional advantage in RV gene studies because the 5' ends of the RV gene segments start with the nucleotide $\mathrm{G}$, which is favored by T7 RNA polymerase for transcription initiation [91, 92]. In later studies, using the same platform, Komoto and colleagues expressed a recombinant $\mathrm{RV}$ with the backbone from a helper KU strain. The recombinant virus expressed a broadly antigenic SA11-derived VP4, which was capable of inducing antibodies that effectively neutralized different DS-1 strains. This chimeric RV expressing the VP4 gene made it possible to introduce immunodominant and universal epitopes into the VP4 segment for better vaccine design and development of diagnostic tests [93]. Although this gene replacement technology represented a significant step forward in RV genome manipulation, it was largely restricted to rescuing recombinant viruses expressing heterologous VP4 or VP7 genes, because only neutralizing antibodies targeting the two outer capsid proteins (VP4 and VP7) are able to recognize and remove the helper RV so that novel VP4or VP7-expressing recombinant RVs can be selected. This limits its broad application for generating recombinant RVs expressing other genes that are not targets of neutralizing antibodies.

In order to improve the single-gene-replacement system, a 'two-hit' strategy was developed. In this approach, two selection methods were employed. The first selection method involved the use of temperature-sensitive mutants, and the second selection method involved the use of RNA interference (RNAi). Using this 'two-hit' approach, recombinant RVs with chimeric NSP2 genes were generated. Briefly, the protocol involved cloning of the NSP2 segment of the RV 
into a T7 RNA polymerase promoter plasmid (developed previously by Komoto and colleagues) [89] and introducing this construct by transfection into COS-7 cells that had been infected with a T7-polymerase-expressing vaccinia virus. After transfection, the first selection was introduced by infecting with a helper virus carrying a temperaturesensitive NSP2 segment and incubating at $30^{\circ} \mathrm{C}$. The second selection step involved passaging of the viruses in the supernatant of the transfected COS-7 cells on genetically modified MA-104 cells that had been transduced with lentivirus incorporating a hairpin RNA targeting the NSP2 of the helper virus. This dual selection permitted the successful rescue of recombinant RVs containing segments whose encoded proteins are not targets of neutralizing antibodies. Although the "two-hit" approach has expanded the scope of the gene replacement method, it has the disadvantage of low rescue efficiency, which restricts its application [94, 95]. To address this challenge, Troupin and colleagues developed a gene segment rearrangement approach. This method resulted in the rescue of infectious RV by transfection with an exogenously rearranged RNA segment 7 [96] containing a partial head-to-tail duplication [84, 97]. The duplicated sequence occurs after the stop codon of the ORF and thus does not affect protein synthesis. Such sequence duplications are observed in a variety of RV genes, including segments $5,6,7,8,10$, and 11 , and have been found in natural infections in humans [97, 98] and animals [99]. They can also be reproduced in a cell culture system [100, 101]. Rearranged gene segments have been shown to be preferentially packaged over wild-type segments during the course of viral morphogenesis [97]. These studies suggested the feasibility of using a gene rearrangement to generate recombinant RVs targeting segments that contain a duplicated sequence. To do this, an exogenously rearranged genome segment of interest is introduced into cells infected with the helper virus. The homologous segment of the helper virus will be replaced by the introduced rearranged segment. Because the rearranged segment is preferentially selected for packaging into progeny virions, the selection step of blocking the incorporation of the homologous segment from helper virus into recombinant virus particles is eliminated. Previous studies on RGSs of reoviruses that are closely related to RVs demonstrated that the use of an engineered baby hamster kidney cell (BHK) line expressing T7 RNA polymerase (BHK-T7 cells) resulted in virus rescue efficiency similar to that observed in the system dependent on the use of live vaccinia virus, indicating that vaccinia virus can be eliminated from the procedure for rescuing RVs [102]. In 2016, an avian-mammalian reassortant RV was generated using a helper-virus-dependent RGS. This system, developed by Johne and colleagues [103], eliminated the use vaccinia virus as source of T7 RNA polymerase, which was instead provided by BSR5/T7 cells (synonymous with BHK-T7 cells). Transfection with transcripts derived from cDNA or single-stranded RNA in a permissive cell line was sufficient for recovering infectious double-stranded RNA viruses such as orbiviruses [104, 105]. Interestingly, this facile approach involving only transfection of cells with plasmid-derived RNAs failed to result in recovery of infectious RV [85]. Instead, the segment rearrangement approach resulted in the rescue of infectious RVs that retained heterologous segments 5-11. Subsequent studies revealed the presence of unintended, spontaneous sequence rearrangements in either the wild-type segments from the helper virus or in the exogenously rearranged genes [106]. This secondary gene arrangement complicates the characterization of the rescued RVs, and the interpretation of experimental results.

\section{Plasmid-only-based RGSs}

Significant efforts invested in the development of an entirely plasmid-based RV RGS over the past several years led to success in 2017 when the first successful plasmid-onlybased RGS was developed for simian RV strain SA11 [107]. This system involved 11 plasmids encoding cDNAs for each full-length individual segment with each RV cDNA flanked by a T7 RNA polymerase promoter and an HDV ribozyme sequence. Three additional polymerase-II-promoter-driven expression plasmids were also included in the first system. These three plasmids express the fusion-associated small transmembrane protein (FAST) of Nelson Bay virus (NBV), and the vaccinia virus capping enzyme subunits D1R and D12L, respectively.

While group B RVs encode a FAST homolog [108], group A RVs lack this protein. Such fusogenic proteins have been identified in members of the genera Aquareovirus and Orthoreovirus of the family Reoviridae and have been shown to promote viral replication $[109,110]$. The transcripts from the 11 expression plasmids may lack a 5' cap, and thus the addition of an expression plasmid encoding the vaccinia virus capping enzyme subunits D1R and D12L was found to increase capping efficiency for viral mRNAs and, as a result, increase the rate of viral protein translation [84, 102]. All $11+3$ plasmids were introduced by transfection into BHK-T7 cells, followed by inoculation of lysates onto MA-104 cells to rescue viable viruses. Although the concurrent transfection with plasmids encoding the capping enzyme and FAST protein was demonstrated to increase the rescue efficiency of RGS-derived RV, the efficiency may be variable for lesspathogenic RV strains, which are difficult to propagate in the cell culture system. Although MA-104 cells are permissive to RV infection, the host innate immune response may restrict rescue of RGS-derived virus and limit subsequent virus propagation. A follow-up study also demonstrated that the use of a plasmid encoding vaccinia virus capping 
enzyme subunits may not provide an additional advantage for virus rescue as initially expected [111] . Although omitting the additional three plasmids coding for the FAST protein and the vaccinia virus capping enzymes did not prevent the successful rescue of the virus, the overall rescue efficiency was poor. Rescue efficiency of RV strain KU could be improved by using the 11 plasmids without the accessory capping enzyme plasmids when a 3-fold higher concentration of the NSP2 and NSP5 plasmids was used, and when the transfected BHK-T7 cells were co-cultured with CV-1 cells [112, 113]. An enhanced RV reverse genetics system was recently reported in which further modifications and improvements were made [114]. In addition to the 11 plasmids encoding each of the RV gene segments, this new system incorporated one additional plasmid, named C3P3-G1. This chimeric cytoplasmic capping-prone phage polymerase (C3P3-G1) plasmid encodes a chimeric protein consisting of an ASFV (African swine fever virus) capping enzyme to increase capping and stability of viral transcripts and a T7 DNA-dependent RNA polymerase from vaccinia virus to enhance viral transcription $[115,116]$. The use of this fusion plasmid substantially improved the rescue efficiency of an RV-related reovirus [116]. An additional modification was made in MA-104 cells, which are routinely used in the transient transfection to produce infectious RVs. To disable the antiviral innate immune response, an engineered MA-104 cell line was isolated that stably expresses the $\mathrm{V}$ protein of parainfluenza virus 5, targeting STAT1 for degradation, and the $\mathrm{N}$ protease of bovine viral diarrhea virus (BVDV), targeting IRF3 for degradation $[114,117]$. This stable cell line in which the innate immunity was found to be significantly attenuated, is named MA104N $\mathrm{N}^{*} \mathrm{~V}$. The improved RGS for $\mathrm{RV}$ with the two new features described above has demonstrated a higher rescue efficiency for human and animal RVs when compared to the traditional RV RGS methods, and this should facilitate studies investigating gene functions in virus replication and pathogenesis. A schematic representation of $11+3$ and $11+1$ plasmid-only based RGSs is shown in Figure 2. A list of existing RGSs with their limitations and advantages is shown in Table 2 .

\section{Using RGSs to study the infection biology of RVs}

Until the advent of RV RGSs, researchers relied heavily on the use of traditional approaches such as cell-culturebased reassortment, in vitro transcription, and selection of temperature-sensitive mutants to study the molecular and chemical details of RV replication [32, 95, 118]. Komoto and colleagues [119] generated a recombinant virus with mutations in the trypsin cleavage site of the VP4 segment of RV strain SA11. Rotavirus spike protein (encoded by the VP4 gene) is first synthesized as an inactive precursor. The precursor spike protein can attach to the cellular receptor but cannot mediate virus-cell fusion. Thus, the proteolytic cleavage of VP4 is essential for viral entry. The proteolytic cleavage site in the spike protein can be monobasic (containing a single basic amino acid in the critical position of the cleavage site) or multibasic (containing several basic amino acids in the critical position of the cleavage site), which has been demonstrated in viral envelope proteins of several viruses, including the HAs of avian influenza A viruses [120]. The RV VP4 gene contains a monobasic cleavage site, where it is cleaved to form VP5* and VP8* [121]. Of the three positively charged arginine residues (R231, R241, and R247) in the monobasic cleavage sites of VP4, R247 is thought to play an additional role in enhancing RV infectivity, although the other two sites can also be cleaved by trypsin $[122,123]$. The introduction of an additional arginine amino acid near position 247of the VP4 gene results in the generation of a polybasic cleavage site. Monobasic cleavage sites are usually cleaved by exogenous proteases such as trypsin (in the intestine) or serine proteases similar to trypsin (in the respiratory tract). The distribution of trypsin and trypsinlike serine proteases is limited, as these are either membrane-bound or secreted in the lumen of the intestinal and respiratory tract $[124,125]$. The multibasic cleavage site, however, is usually cleaved by furin-like serine proteases, which are ubiquitous in their distribution and found inside cells. The rationale behind the generation of an RV with a furin cleavage site in the spike protein was to allow the virus to undergo multiple rounds of replication without the need for exogenous trypsin, as was done previously with influenza virus $[119,126]$. Using the helper virus RGS, a recombinant virus with a polybasic cleavage site in the VP4 gene was successfully recovered. In the absence of exogenous protease, this recombinant virus replicated but failed to form plaques. This suggests that the cleavage of the precursor spike protein that is necessary for viral entry was mediated by furin. It has been suggested that furin cleavage may result in intracellular retention of virions by forming a stable complex or may result in prematurely activated virions $[119,127]$. However, the engineered RV with a polybasic cleavage site at position 247 of VP4 was capable of being propagated in MA104 cells in the presence of an exogenous protease such as trypsin, although the virus titers were lower than those of the wildtype RV. Although the exogenous trypsin probably cleaves the spike protein at one of the monobasic cleavage sites (R231 or R241), the lower replication titer suggests that trypsin cleavage at position 247 of VP4 may be associated with enhanced infectivity. One possible explanation for the observed lower replication titer is that untrypsinized spikes are disordered and conformationally different from 


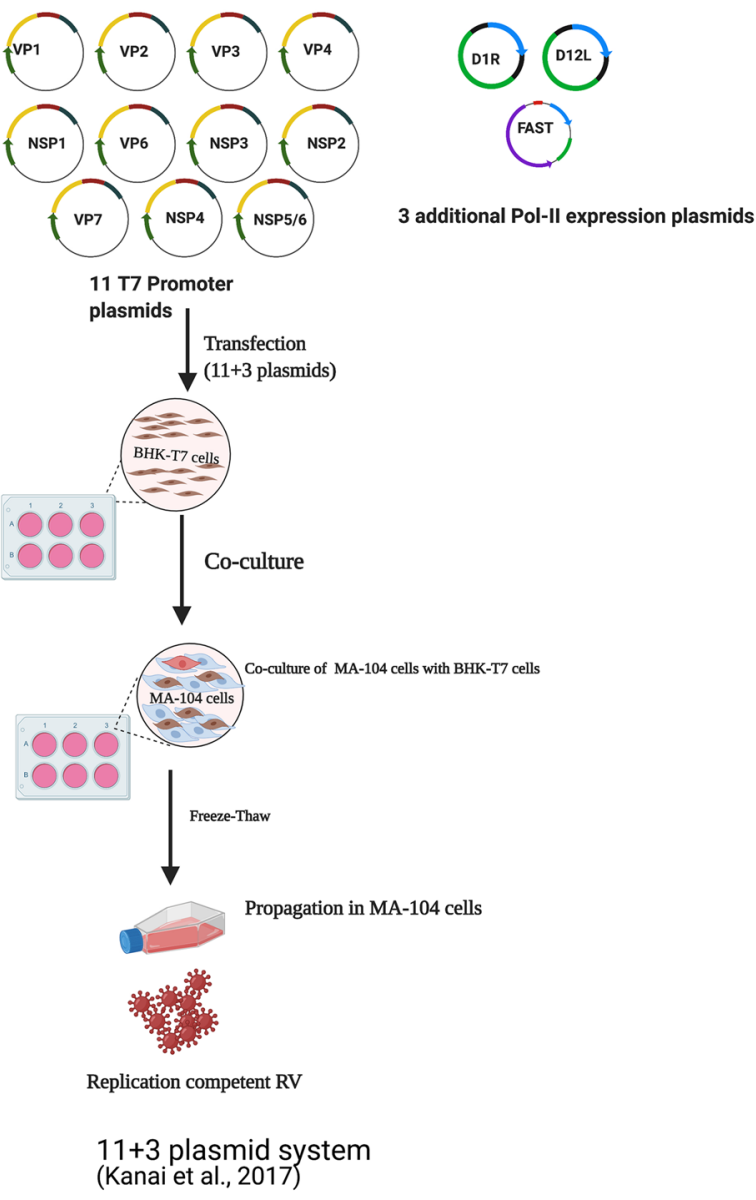

Fig. 2 Schematic representation of two major entirely plasmid-based RGSs. The $11+3$ plasmid-based RGS was developed first [107]. In the $11+3$ plasmid platform, cDNAs corresponding to 11 segments are each flanked by a T7 promoter and an HDV ribozyme. Eleven plasmids along with three accessory polymerase-II-promoter-driven expression plasmids encoding the FAST protein (fusion-associated small transmembrane protein) and two vaccinia virus capping enzyme subunits are introduced by transfection into BHK-T7 cells, which are co-cultured with MA-104 cells after 2 days. After freeze-thawing, cell lysates are inoculated onto MA-104 cells, followed by additional

the trypsinized spikes of RV. Trypsin cleavage of VP4 is essential for the conformational changes in the spikes that are necessary for virus-cell fusion. [119, 128].

Segment 11 has two open reading frames (ORF) with an alternative ORF $(\mathrm{a}+1)$ encoding the NSP6 protein [129, 130]. Little is known about the function of NSP6 in RV replication, although this protein has been shown to be localized in the viroplasm and interact with NSP5 and NSP2 and that this is essential for viroplasm formation $[130,131]$. Several reports have shown that NSP6 inhibits apoptotic cell death of RV-infected cells and interferes with IFN signaling [132-136]. These data appear to suggest that the NSP6 protein may promote RV replication by linking the mitochondria and viroplasm together. However, using the RGS

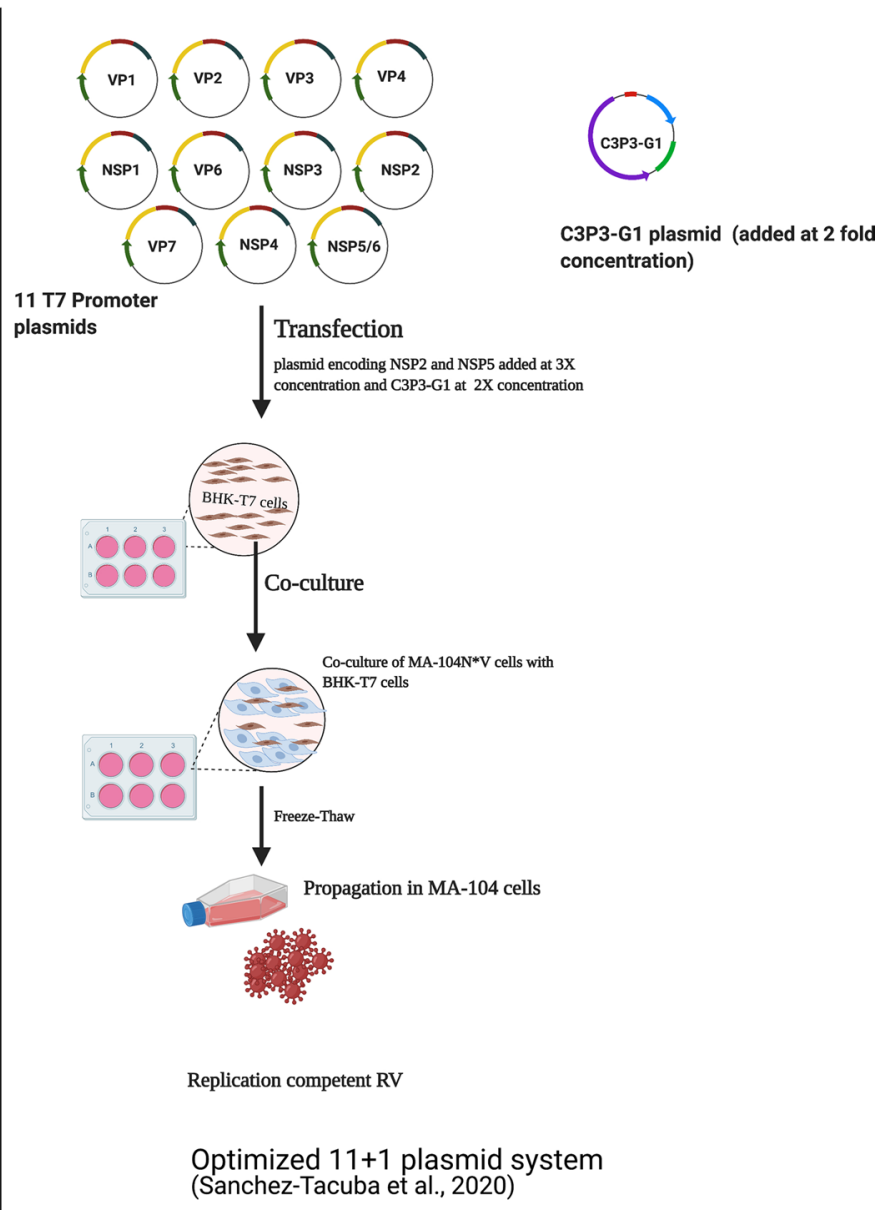

incubation and rescue of viable progeny. The optimized $11+1$ plasmid platform replaces the three accessory plasmids with a single plasmid, named C3P3-G1plasmid, a cytoplasmic expression plasmid with both 5' capping and RNA synthesis activity [114]. After transfection of BHK-T7 cells with the 11+1 plasmids with NSP2 and NSP5 added at a 3-fold higher concentration than the other plasmids, the supernatant is applied to BHK-T7 and genetically modified MA104N*V cells. The supernatant obtained in this co-culturing step is then propagated in MA-104 cells.

platform, researchers have demonstrated that NSP6 is not essential for virus replication in a cell culture model [111]. The functional discrepancy of NSP6 among these studies may be reconciled by earlier observations in which several human and animal RV strains isolated from natural infections possessed a truncated NSP6 or lacked an initiation codon [137, 138]. In the light of recent experiments, the function of NSP6 in RV replication in mammalian hosts requires further investigation. The enhanced RGS discussed above should enable the function of NSP6 in RV replication and pathogenesis to be investigated.

To study the role of NSP1 in RV replication, a truncation of 103 amino acids was introduced in the $\mathrm{C}$-terminal region of NSP1, and IFN levels in cells infected with wild-type and 
Table 2 Existing reverse genetics system for rotaviruses

\begin{tabular}{|c|c|c|c|c|}
\hline Helper virus-dependent RGSs & Year & Advantages & Limitations & Reference \\
\hline Helper-virus driven RGS & 2006 & First RGS developed for RV & $\begin{array}{l}\text { Limited to segments that generate neu- } \\
\text { tralizing antibodies (VP4, VP7). }\end{array}$ & [89] \\
\hline Gene rearrangement system & 2010 & $\begin{array}{l}\text { Eliminated the need for a selection } \\
\text { system, not limited to VP4 or VP7 } \\
\text { segments }\end{array}$ & $\begin{array}{l}\text { Requires exogenous gene rearrange- } \\
\text { ment, low yield of progeny virus with } \\
\text { rearranged gene segments }\end{array}$ & [96] \\
\hline Two-hit system & 2010 & $\begin{array}{l}\text { Not limited to VP4 or VP7 segments, } \\
\text { higher titer of recombinant progeny } \\
\text { virus compared to existing system }\end{array}$ & $\begin{array}{l}\text { Requires temperature-sensitive mutants } \\
\text { and RNAi for selection of helper virus }\end{array}$ & [94] \\
\hline $\begin{array}{l}\text { Helper virus system with BHK-T7 cells } \\
\text { used for transfection }\end{array}$ & 2016 & $\begin{array}{l}\text { Eliminated the use of vaccinia virus as } \\
\text { the source of T7-RNA polymerase } \\
\text { and replaced it with BHK-T7 cells } \\
\text { that constitutively express T7-RNA } \\
\text { polymerase }\end{array}$ & $\begin{array}{l}\text { Still requires temperature-sensitive } \\
\text { helper virus for selection. }\end{array}$ & [103] \\
\hline Plasmid-only-based RGSs & Year & Advantages & Limitations & Reference \\
\hline $\begin{array}{l}\text { Entirely plasmid-based RGS ( } 11+3 \text { plas- } \\
\text { mid system) }\end{array}$ & 2017 & $\begin{array}{l}\text { First successful entirely plasmid-based } \\
\text { RGS for rotavirus }\end{array}$ & Low rescue efficiency & {$[107]$} \\
\hline $\begin{array}{l}\text { Entirely plasmid-based RGS (11 plasmid } \\
\text { system) }\end{array}$ & 2018 & $\begin{array}{l}\text { Eliminated the need for additional } \\
\text { plasmids, optimized existing plasmid- } \\
\text { based RGS by adding plasmids coding } \\
\text { for NSP2 and NSP5 at 3-fold higher } \\
\text { concentration than the other plasmids. }\end{array}$ & $\begin{array}{l}\text { Relatively low rescue efficiency compared } \\
\text { to the } 11+1 \text { plasmid system }\end{array}$ & {$[112]$} \\
\hline $\begin{array}{l}\text { Simplified 11+1 RGS system (NP868R- } \\
\text { based RGS) }\end{array}$ & 2019 & $\begin{array}{l}\text { Eliminated the need for } 3 \text { additional } \\
\text { plasmids by using a single additional } \\
\text { plasmid }\end{array}$ & & [164] \\
\hline $\begin{array}{l}\text { Optimized } 11+1 \text { plasmid system (C3P3- } \\
\text { G1 based RGS) }\end{array}$ & 2020 & Optimized for higher rescue efficiency & & [114] \\
\hline
\end{tabular}

mutant RVs were compared. Cells infected with the WT virus had a reduced level of IRF3, while mutant RV showed a normal amount of IRF3. A luciferase assay revealed an activated IFN- $\beta$ promoter element in cells infected with mutant RV. This suggested that NSP1 is essential for subverting the host immune response by downregulating IRF3. Using RGS-derived RV with truncated NSP1, researchers were able to demonstrate that NSP1 is essential for blocking the host IFN response, which is in good agreement with previous findings [107, 139-141]. In order to study the role of NSP5 in RV replication, recombinant RVs harboring mutations in NSP5 were generated using a plasmid-based RGS. The NSP5 mutation led to impaired viroplasm formation, showing that hyperphosphorylation of NSP5 is crucial for viroplasm formation [142]. Along the same line, researchers showed that VP3 is involved in antagonizing the RNase L signaling pathway. Upon virus infection and IFN induction, RNase L signaling is activated, resulting in degradation of viral RNA and subsequent inhibition of viral replication. The virus with a non-functional VP3 protein was attenuated because of the absence of a viral virulence factor that could effectively neutralize the RNase L-associated innate restriction. VP3 mutants can be further explored as next-generation vaccine candidates for the control of RV infection in humans [143].

Efforts to understand RV entry, the first important step in the virus life cycle, have been aided by the availability of RGSs. In a mouse model, it was shown that RV infection leads to inflammation and obstruction of bile ducts, a condition known as biliary atresia. An RGS-based study revealed that arginine (R) at position 446 of the VP4 protein is essential for the viral entry process, which is consistent with previous work showing that a VP4 mutant with the arginine at this position replaced by glycine had reduced binding affinity for epithelial cells in the biliary duct and that VP4 is responsible for tropism for cholangiocytes. It has been shown recently that the spike protein (VP4) of rhesus RV can bind to heat shock protein 70 (Hsc70) present on cholangiocytes and mediate entry into these cells. The detailed mechanism, including the cellular response after VP4 attachment remains to be elucidated [144, 145].

During the short time span after its initial development, plasmid-only-based RV RGSs have been used extensively in diverse areas of RV research, including studies of the functions of RV proteins [146], the generation of RV reassortants 
[147], stable RV reporter expression systems [148], and novel vaccine platforms [149]. Thus, it can be envisioned that RGSs will be extensively employed in the rotavirus field in the future to study multiple facets of rotavirus biology that were not possible to investigate prior to the era of rotavirus RGSs.

\section{Generation of a reporter rotavirus using an RGS}

Reporter viruses can allow for real-time study and direct visualization of viral replication, cross-species transmission, and pathogenesis, both in vivo and in vitro [42]. The RV capsid has the potential to incorporate an additional $\sim 1800$ bp of dsRNA [150] without a substantial effect on virus replication. However, large exogenous gene segments may make RV rescue very inefficient in the RGS $[151,152]$. Furthermore, the insertion of a foreign gene can disrupt the structure of the dsRNA that contains the packaging signals [153, 154]. It should be noted that the RV packaging signals have so far not been identified; they are likely to reach beyond the 5' and 3' UTRs into the ORF of the segment. Despite these challenges, several RV reporters have been developed using a plasmid-only-based RGS. A RV reporter was generated by the fusion of split GFP fragments to the C-terminus of NSP1 and by inserting NanoLuc luciferase into the $\mathrm{N}$-terminus of NSP1 [107]. Insertion of large (516-bp) foreign genes such as NanoLuc luciferase did not have an adverse effect on viral replication. NSP1 has been demonstrated to be dispensable for viral replication in cell culture [155-157]. Successful replication and rescue of NSP1 mutant virus using an RGS have shown that segment 5 can functionally tolerate the insertion of foreign genes [112]. Additional NSP1-based RV reporters with mCherry or EGFP inserted into the N-terminal region of the NSP1 gene were successfully rescued by leveraging the plasmid-only-based RGS [112].

Using an optimized plasmid-only-based RGS, a repertoire of recombinant RVs expressing a fluorescent reporter protein were recently generated in which the native ORF of NSP3 was replaced with ORFs encoding NSP3 fusion proteins with each of six fluorescent reporter proteins (UnaG, mKate, mRuby, TagBFP, CFP, YFP) fused to the C-terminus [158-160]. In addition to NSP1 and NSP3 segments, NSP2 was also exploited to generate an RV reporter system in a very early study. Using the dual selection method, rearranged and heterologous sequences were inserted into the 3'-UTR of the RV NSP2 gene, while a engineered internal ribosomal entry site from cricket paralysis virus was inserted into the NSP2 segment [161].

Since the RV core has 12 fivefold axes, ideally, each segment, along with its polymerase complex, takes one designated space. This theory supports the idea that the RV core has the capacity to accommodate an extra segment and its associated polymerase complex $[69,162]$. It has also been shown that the RV core can package an extra $1800 \mathrm{bp}$ as part of the viral genome [150]. Using an RGS-based approach, recent studies showed that segment 7, encoding NSP3, could tolerate a 774-bp insertion without substantially compromising RG replication in vitro [114, 163]. Specifically, researchers were able to expand the RV genome by replacing the ORF of segment 7 with an NSP3 fusion protein in which a fluorescent reporter protein had been inserted into the C-terminus of NSP3. The 2A peptide, which cleaves a protein fused on either side of it into two separate proteins, was placed between NSP3 and the reporter protein, allowing them to be produced simultaneously. In light of the fact that the NSP3 segment is transcribed more efficiently than the other segments, NSP3 has emerged as an attractive segment for developing a sensitive reporter system to study RV biology [164]. This has been impressively demonstrated with an NSP3-mRuby recombinant SA11 reporter virus to study the underlying mechanism of abnormal calcium signaling during the course of RV infection [160].

\section{Generation of reassortant RVs using an RGS}

The segmented nature of the RV genome makes it possible for genome reassortment to occur when two viruses of different origins coinfect a cell, contributing to the genetic diversity of group A RVs. Such reassortment can occur within or between host species, leading to the emergence of novel strains and posing a challenge to the effectiveness of vaccines used in the field [10,22,165-167]. There is limited information on gene assortment and packaging of RVs, although some biophysical studies have started to shed light on this problem [73]. In RVs, synthesis of dsRNA occurs after assortment and packaging of each of the 11 segments. Compared to some other segmented viruses, RV assortment and packaging are poorly understood. Based on in silico experiments, it is presumed that assortment and packaging of RV segments do not occur segment by segment but rather through the formation of supramolecular complexes formed by interactions of all 11 segments, which are then encapsidated by the core-shell protein VP2. The interactions of all ss(+) RNA segments to form the supramolecular complex are probably guided by the recognition of a presumed highorder RNA structure at 3'-terminal region, as observed in in silico analysis of RVA RNA [168], and it was shown that disruption of this interaction inhibited viral infectivity [169]. Further in vitro studies need to be carried out to confirm the results of the in silico experiments. Phylogenetic analysis of the VP1 segment, which codes for the RNA polymerase, have divided RV groups into two clades: clade A, with groups $\mathrm{A}, \mathrm{C}, \mathrm{D}$, and $\mathrm{F}$, and clade $\mathrm{B}$, with groups $\mathrm{B}, \mathrm{G}$, and $\mathrm{H}$ 
[39]. There is limited opportunity for reassortment between members of different groups, whereas clades within a group have high frequencies of genetic reassortment. Reassortant progeny viruses may have fitness advantage, whereas the progeny viruses with incomplete segment or gene combinations are not viable. Fitness costs may increase in progeny viruses derived from more genetically distant parenteral strains. Fitness costs due to reassortment may lead to attenuation of viruses that can be further explored as vaccine candidates [38].

The traditional system of generating a reassortant virus was labor-intensive and time-consuming. Recent RGSs for $\mathrm{RV}$ s have decreased the time and effort required to generate desirable reassortant viruses from months to weeks. Thus, RGSs are highly suitable for rapid generation of vaccine candidates in cases of emergence of novel RV strains of clinical significance [88]. An RV RGS has been successfully used to generate human RV reassortants. Using a helper virus system, recombinant RVs containing NSP2 from Wa-like or AU-1-like strains in an SA11 backbone were generated [170]. Similarly, an avian-mammalian reassortant virus with VP4 from chicken RVA strain 02V0002G3 in an SA11 backbone was generated, but the rescue of a bovine-VP4/ SA11 recombinant virus failed [103]. After the successful generation of an $11+3$ plasmid-only-based RGS, numerous reassortant RVs have been generated using this platform. For instance, a replication-competent VP6-KU/SA11 recombinant RV was generated in 2017 [107], and a chickenmammalian reassortant virus, previously developed using a helper virus, was rescued using this system as well [171]. In addition, a panel of reassortant viruses with VP4 from bovine, bat, porcine, and pheasant RVs in an SA11 backbone were successfully rescued. However, rescue of reassortant Turkey VP4/SA11 and human (Wa) RVA VP4/SA11 remained unsuccessful [171]. In addition, efforts to generate an RGS for avian RV strain 02V002G3 and to generate mono-reassortant avian-mammalian RV for each segment had limited success using the 11+3 RGS platform. Nevertheless, replication-competent reassortant viruses containing exogenous VP3 and VP4 segments were generated using an 11+3 RGS [172]. Similar bottlenecks were also observed in generating SA11 reassortant RVs with VP4, VP7, or both VP4 and VP7 from African human RVA strains. These outer capsid protein sequences (VP4 and VP7) were from African human RVA strains GR10924/99, Moz308 (DS-1 like genotype constellation), and Moz60a (Wa-like constellation), respectively. Interestingly, either the VP4 or VP7 segment alone from one of the above three strains was reassorted into the genetic SA11 backbone successfully. However, efforts to generate recombinant RV with VP4 and VP7 segments in combination with one of these three strains in SA11 backbone were not successful [173].
Using the enhanced RGS $(11+1$ plasmids), researchers successfully rescued a murine-like RV designated as $\mathrm{rD6} / 2$ like. This rD6/2-like RV possessed segment 4 from simian RV strain RRV, segments 1 and 10 from SA11, and the remaining segments from the murine EW strain. This platform was also used to generate bovine-human recombinant $\mathrm{RV}$, with VP4 from the bovine UK strain in a human CDC-9 backbone. This was remarkable, as such recombinants were hard to rescue using an earlier RGS [114]. Using 11 plasmids, a panel of 11 reassortant viruses, each having a single gene segment from human strain KU in the backbone of SA11, were generated. In addition to monogenic reassortant $\mathrm{RVs}$, triple gene reassortant viruses (VP1, VP2, VP3) and multiple VP7 reassortant viruses belonging to genotypes G1-G4, G9, and G12 were also produced [88]. Diverse RVs harboring genetic segments from different species, generated from forced reverse genetics experiments as discussed above, can be utilized to study the replication fitness, host range restriction, and pathogenesis of RVs.

\section{RGSs for production of next-generation RV vaccines for humans and animals}

Rotaviruses are important gastrointestinal pathogens, causing 125,000-200,000 deaths annually in children less than 5 years old [16]. Various forms of vaccines are either licensed and in use or in the developmental phase. The use of three live attenuated vaccines in infants and children has substantially reduced $\mathrm{RV}$-associated child mortality across the globe [174-177]. The Asian and African countries that account for the majority of deaths due to RV infections have 20-30\% lower vaccine efficacy than developed countries [176, 178, 179], which provides a strong justification for developing more efficacious vaccines for reducing disease mortality and morbidity in the developing world [180]. The efficacy and safety of existing vaccines are of concern, and thus continuous investment in understanding the mechanism of protection and generation of novel RV vaccine with desirable features is of utmost importance [181, 182]. Of the currently available human RV vaccines, four are monovalent (Rotarix, Rotavac, Rotavin, Lanzhou), and two are pentavalent (RotaTeq and RotaSIIL), with one new monovalent vaccine, RV3-BB, undergoing a phase II clinical trial [177, $183,184]$. In children, the initial infection does not provide sterile immunity to reinfection, although it limits the clinical severity of subsequent infections [185]. A monovalent vaccine relies on the production of a homotypic immune response after the initial administration and a heterotypic response after repeated administration [186, 187]. Heterotypic protection could be due to non-neutralizing antibodies, especially antibodies against VP6, VP2, NSP2, and NSP4. Such non-neutralizing antibodies could still be pivotal in 
eliciting protection against the disease [188-190]. Current live attenuated RV vaccines depend on natural attenuation, with the mechanisms of attenuation being largely unknown. Two major vaccines licensed for international use have their own caveats. There is limited information on protection against heterotypic strains by Rotarix and RotaTeq. Rotarix is a monovalent vaccine containing the human RV strain G1P[8]. RotaTeq is a pentavalent vaccine that incorporates five mono-reassortant rotaviruses of genotypes, G1, G2, G3, $\mathrm{G} 4$, and $\mathrm{P}[8]$ from human strains in a bovine $\mathrm{WC} 3$ rotavirus backbone. The bovine strain used as the backbone for the generation of the attenuated human reassortant virus confers no broad protection and has limited replication capacity in humans [191]. The currently available RV vaccines are live attenuated strains, and as such, various underlying causes such as the presence of maternal antibodies, environmental enteric dysfunction, and malnutrition can lead to decreased vaccine efficacy [178, 179, 192]. Administration of live RV vaccines has been associated with intussusceptions, and these vaccines should not be administered to immunocompromised or prematurely born children [193]. In addition, live attenuated vaccines carry the risk of reassortment with wild-type human RVs [61]. Thus the combination of all these factors calls for the development of next-generation $R V$ vaccines, including non-replicating $R V$ vaccines that can be administered parenterally [194]. RGSs have been used successfully to develop non-replicating or attenuated vaccines for influenza virus [195]. Multiple approaches have been used for the generation of attenuated influenza virus vaccines, including introduction of mutations in the cleavage site of haemagglutinin (HA segment) [196], truncations in $\mathrm{NS} 1$, which is essential for counteracting the innate immune response, deoptimizing codons, generation of pseudotype viruses, and generation of reassortants by rearranging the viral genome [195]. All of these approaches can be applied to RV vaccine design using the enhanced RV RGS.

In developed countries, there has been in increase in the incidence of norovirus-associated diarrhea in children [197]. Recently, using a plasmid-based RV RGS, two separate proteins (NSP3 and a fluorescent reporter protein) were synthesized by replacing the native ORF of segment 7 with an ORF encoding an NSP3-GFP fusion protein [163]. Thus, the use of an RGS has opened the possibility of using RVs as expression vectors for development of bivalent vaccines for enteric viruses. The RGS-based platform will be pivotal in the development of better vaccine candidates, as it allows the experimental conditions to be tightly regulated [152, 198, 199]. RGSs allow for the desired combination of various gene segments, simultaneous mutations in various gene segments, reassortments of different strains, and generation of mutants with a blunted IFN response, which together will help to advance the development of next-generation RV vaccines [107].
Rotavirus can infect a wide variety of livestock and companion animals [200]. Zoonotic transmission of RVs is reported occasionally, and this poses a significant risk to humans, as vaccines may not be protective against infection by novel zoonotic strains [10, 201]. RV infection is associated with economic loss to the livestock industry due to a decline in production and increased treatment costs. Group A and B rotaviruses primarily infect calves and lambs [202-204]. Group A, B, and C RVs are frequently associated with diarrhea in piglets [203, 205], although group H RVs have also been detected in recent years [206, 207]. Group D, $\mathrm{F}$, and G RVs are exclusively associated with avian species, with group A being most prevalent in poultry [8]. Group A $\mathrm{RV}$ s are a leading cause of diarrhea in young foals. Rotavirus vaccines are available for cattle, pigs, and equines. Rotavirus vaccines for animal use are mainly protective against group A RV strains, as the vaccine's composition is largely based on group A RV strains [208]. Since RV strains from other groups are also clinically important and afflict animals, there is a demand in the field for broadly protective $\mathrm{RV}$ vaccines. Almost all RV vaccines for animals are live attenuated viruses, and thus the propagation of seed virus to high titers is essential. Since non-group-A rotavirus strains are hard to propagate to high titers, this represents a major obstacle for the development of a multivalent RV vaccine. The RV vaccines currently available for animal use rely on the immunization of pregnant animals. Thus, protection of newborns is dependent on maternal antibody transfer, and this mechanism can vary depending on the route of administration, health status of the mother, and previous exposure of the mother to RV. The advent of plasmid-only-based RGSs for RVs will enable rational design of animal RV vaccines such as subunit vaccines, eliminating the need to propagate non-group-A RV [9, 206, 208, 209].

\section{Conclusion}

Before the advent of entirely plasmid-based RGSs for RVs, efforts to study the phenotype-genotype relationship of RVs primarily depended on the traditional approach involving the introduction of mutations into the genome and evaluation of protein function in an expression system, which is time-consuming and labor-intensive, and the genotypephenotype correlation can be ambiguous. Utilization of an entirely plasmid-based RV RGS will enable rapid interrogation of viral gene functions in great detail. Despite extensive studies on virus structure, replication, packaging signals, segment assortment, many key steps and underlying mechanisms of RV replication are poorly understood. Knowledge gaps remain in certain areas such as heterotypic immunity to infection, correlates of protection, factors affecting viral spread, mechanism of selective packaging, and host range 
restriction. On the other hand, although the currently available vaccines have significantly reduced mortality in the developed world, vaccine efficacy, safety, and cost still pose a significant challenge to developing countries. Considering that more than two-thirds of the RV-associated child mortality occurs in developing countries and the least developed countries, next-generation RV vaccines with increased safety, efficacy, and reduced cost are necessary, and these benefits also apply to rotavirus vaccines for livestock and poultry. The recent success of plasmid-only-based RGSs has paved the way to develop next-generation RV vaccines. A platform similar to those used to develop improved vaccines for other segmented viruses such as influenza should be applied to RVs. There is little doubt that cost-effective RV vaccines with higher safety and desirable efficacy will emerge from the RGS platform, which will be used eventually to protect humans and agricultural animals from RV infections.

Supplementary Information The online version contains supplementary material available at https://doi.org/10.1007/s00705-021-05142-7.

Acknowledgements We thank all of the members in our laboratory for reading the manuscript and suggesting corrections.

Funding This work was supported in part by the Agricultural Experiment Station of the University of Kentucky and the William Robert Mills Endowment Fund.

\section{Declarations}

Conflict of interest The authors declare that there are no conflicts of interest.

\section{References}

1. Adams WR, Kraft LM (1963) Epizootic diarrhea of infant mice: indentification of the etiologic agent. Science 141(3578):359-360

2. Malherbe H, Harwin R (1963) The cytopathic effects of vervet monkey viruses. S Afr Med J 37(4):407-411

3. Bishop RF et al (1973) Virus particles in epithelial cells of duodenal mucosa from children with acute non-bacterial gastroenteritis. Lancet 2(7841):1281-1283

4. Flewett TH, Bryden AS, Davies H (1973) Letter: Virus particles in gastroenteritis. Lancet 2(7844): 1497

5. Trojnar E et al (2010) The genome segments of a group D rotavirus possess group A-like conserved termini but encode groupspecific proteins. J Virol 84(19):10254-10265

6. Walker PJ et al (2019) Changes to virus taxonomy and the International Code of Virus Classification and Nomenclature ratified by the International Committee on Taxonomy of Viruses (2019). Arch Virol 164(9):2417-2429

7. Matthijnssens J et al (2012) VP6-sequence-based cutoff values as a criterion for rotavirus species demarcation. Arch Virol 157(6):1177-1182
8. Deol P et al (2017) Avian group D rotaviruses: structure, epidemiology, diagnosis, and perspectives on future research challenges. Pathogens 6(4):53

9. Alaoui Amine $\mathrm{S}$ et al (2020) Evidence for zoonotic transmission of species A rotavirus from goat and cattle in nomadic herds in Morocco, 2012-2014. Virus Genes 56(5):582-593

10. Martella V et al (2010) Zoonotic aspects of rotaviruses. Vet Microbiol 140(3-4):246-255

11. Sadiq A et al (2019) Molecular characterization of human group A rotavirus genotypes circulating in Rawalpindi, Islamabad, Pakistan during 2015-2016. PLoS ONE 14(7):e0220387

12. Joshi MS et al (2017) Identification of group B rotavirus as an etiological agent in the gastroenteritis outbreak in Maharashtra, India. J Med Virol 89(12):2244-2248

13. Joshi MS, Jare VM, Gopalkrishna V (2017) Group C rotavirus infection in patients with acute gastroenteritis in outbreaks in western India between 2006 and 2014. Epidemiol Infect 145(2):310-315

14. Chen CM et al (1985) Chinese adult rotavirus is a group B rotavirus. Lancet 2(8464):1123-1124

15. Tao H (1988) Rotavirus and adult diarrhea. Adv Virus Res $35: 193-218$

16. Troeger $\mathrm{C}$ et al (2018) Rotavirus vaccination and the global burden of rotavirus diarrhea among children younger than 5 years. JAMA Pediatr 172(10):958-965

17. Rojas MA et al (2017) Identification of two novel Rotavirus A genotypes, G35 and P[50], from Peruvian alpaca faeces. Infect Genet Evol 55:71-74

18. Desselberger U (2014) Rotaviruses. Virus Res 190:75-96

19. Santos N, Hoshino Y (2005) Global distribution of rotavirus serotypes/genotypes and its implication for the development and implementation of an effective rotavirus vaccine. Rev Med Virol 15(1):29-56

20. Hull JJ et al (2011) United States rotavirus strain surveillance from 2005 to 2008: genotype prevalence before and after vaccine introduction. Pediatr Infect Dis J 30(1 Suppl):S42-S47

21. Iturriza-Gomara M et al (2011) Rotavirus genotypes co-circulating in Europe between 2006 and 2009 as determined by EuroRotaNet, a pan-European collaborative strain surveillance network. Epidemiol Infect 139(6):895-909

22. Matthijnssens J et al (2008) Full genome-based classification of rotaviruses reveals a common origin between human Wa-Like and porcine rotavirus strains and human DS-1-like and bovine rotavirus strains. J Virol 82(7):3204-3219

23. Angel J, Franco MA, Greenberg HB (2008) Rotaviruses. In: Mahy BWJ, Van Regenmortel MHV (eds) Encyclopedia of virology. Academic Press, Oxford, pp 507-513

24. Matthijnssens J et al (2008) Recommendations for the classification of group A rotaviruses using all 11 genomic RNA segments. Arch Virol 153(8):1621-1629

25. Matthijnssens $\mathbf{J}$ et al (2011) Uniformity of rotavirus strain nomenclature proposed by the Rotavirus Classification Working Group (RCWG). Arch Virol 156(8):1397-1413

26. Matthijnssens J, Van Ranst M (2012) Genotype constellation and evolution of group A rotaviruses infecting humans. Curr Opin Virol 2(4):426-433

27. Hardy S et al (2010) Reverse genetics in eukaryotes. Biol Cell 102(10):561-580

28. Potgieter AC, Steele AD, van Dijk AA (2002) Cloning of complete genome sets of six dsRNA viruses using an improved cloning method for large dsRNA genes. J Gen Virol 83(Pt 9):2215-2223

29. Nolden $\mathrm{T}$ et al (2016) Reverse genetics in high throughput: rapid generation of complete negative strand RNA virus cDNA clones and recombinant viruses thereof. Sci Rep 6(1):23887 
30. Desselberger U (2017) Reverse genetics of rotavirus. Proc Natl Acad Sci USA 114(9):2106-2108

31. Beitzel B, Hulseberg CE, Palacios G (2019) Reverse genetics systems as tools to overcome the genetic diversity of Lassa virus. Curr Opin Virol 37:91-96

32. Komoto S, Taniguchi K (2006) Reverse genetics systems of segmented double-stranded RNA viruses including rotavirus. Futur Virol 1(6):833-846

33. Imai M et al (1983) Capped and conserved terminal structures in human rotavirus genome double-stranded RNA segments. J Virol 47(1):125-136

34. Gorziglia MI, Collins PL (1992) Intracellular amplification and expression of a synthetic analog of rotavirus genomic RNA bearing a foreign marker gene: mapping cis-acting nucleotides in the 3'-noncoding region. Proc Natl Acad Sci USA 89(13):5784-5788

35. Chen D et al (2001) Features of the 3'-consensus sequence of rotavirus mRNAs critical to minus strand synthesis. Virology 282(2):221-229

36. Ren L et al (2019) Profiling of rotavirus 3'UTR-binding proteins reveals the ATP synthase subunit ATP5B as a host factor that supports late-stage virus replication. J Biol Chem 294(15):5993-6006

37. Patton JT, Spencer E (2000) Genome replication and packaging of segmented double-stranded RNA viruses. Virology 277(2):217-225

38. McDonald SM et al (2016) Reassortment in segmented RNA viruses: mechanisms and outcomes. Nat Rev Microbiol 14(7):448-460

39. Ogden KM, Johne R, Patton JT (2012) Rotavirus RNA polymerases resolve into two phylogenetically distinct classes that differ in their mechanism of template recognition. Virology 431(1-2):50-57

40. Chizhikov V, Patton JT (2000) A four-nucleotide translation enhancer in the 3'-terminal consensus sequence of the nonpolyadenylated mRNAs of rotavirus. RNA 6(6):814-825

41. Deo RC et al (2002) Recognition of the rotavirus mRNA 3' consensus by an asymmetric NSP3 homodimer. Cell 108(1):71-81

42. Gratia M, Vende P, Charpilienne A, Baron HC, Laroche C, Sarot E, Pyronnet S, Duarte M, Poncet D (2016) Challenging the roles of NSP3 and untranslated regions in Rotavirus mRNA translation. PLoS One 11(1):e0145998

43. Groft CM, Burley SK (2002) Recognition of eIF4G by rotavirus NSP3 reveals a basis for mRNA circularization. Mol Cell 9(6):1273-1283

44. Vende P et al (2000) Efficient translation of rotavirus mRNA requires simultaneous interaction of NSP3 with the eukaryotic translation initiation factor eIF4G and the mRNA 3' end. J Virol 74(15):7064-7071

45. Piron $\mathrm{M}$ et al (1999) Identification of the RNA-binding, dimerization, and eIF4GI-binding domains of rotavirus nonstructural protein NSP3. J Virol 73(7):5411-5421

46. Piron $\mathrm{M}$ et al (1998) Rotavirus RNA-binding protein NSP3 interacts with eIF4GI and evicts the poly(A) binding protein from eIF4F. EMBO J 17(19):5811-5821

47. Tortorici MA, Shapiro BA, Patton JT (2006) A base-specific recognition signal in the 5 ' consensus sequence of rotavirus plusstrand RNAs promotes replication of the double-stranded RNA genome segments. RNA 12(1):133-146

48. Barro $\mathrm{M}$ et al (2001) Identification of sequences in rotavirus mRNAs important for minus strand synthesis using antisense oligonucleotides. Virology 288(1):71-80

49. Guglielmi KM, McDonald SM, Patton JT (2010) Mechanism of intraparticle synthesis of the rotavirus double-stranded RNA genome. J Biol Chem 285(24):18123-18128
50. De Lorenzo G et al (2016) An Inhibitory motif on the 5'UTR of several rotavirus genome segments affects protein expression and reverse genetics strategies. PLoS ONE 11(11):e0166719

51. Settembre EC et al (2011) Atomic model of an infectious rotavirus particle. EMBO J 30(2):408-416

52. McClain B et al (2010) X-ray crystal structure of the rotavirus inner capsid particle at 3.8 A resolution. J Mol Biol 397(2):587-599

53. Aoki ST et al (2009) Structure of rotavirus outer-layer protein VP7 bound with a neutralizing Fab. Science 324(5933): 1444-1447

54. Estrozi LF et al (2013) Location of the dsRNA-dependent polymerase, VP1, in rotavirus particles. J Mol Biol 425(1):124-132

55. Lundgren O, Svensson L (2001) Pathogenesis of rotavirus diarrhea. Microbes Infect 3(13):1145-1156

56. Trask SD et al (2010) A rotavirus spike protein conformational intermediate binds lipid bilayers. J Virol 84(4):1764-1770

57. Ciarlet M, Estes MK (1999) Human and most animal rotavirus strains do not require the presence of sialic acid on the cell surface for efficient infectivity. J Gen Virol 80 (Pt 4)(4):943-948

58. Barbe L et al (2018) Histo-blood group antigen-binding specificities of human rotaviruses are associated with gastroenteritis but not with in vitro infection. Sci Rep 8(1):12961

59. Fleming FE et al (2014) Relative roles of GM1 ganglioside, $\mathrm{N}$-acylneuraminic acids, and alpha2beta1 integrin in mediating rotavirus infection. J Virol 88(8):4558-4571

60. Torres-Flores JM et al (2015) The tight junction protein JAM-A functions as coreceptor for rotavirus entry into MA104 cells. Virology 475:172-178

61. Crawford SE et al (2017) Rotavirus infection. Nat Rev Dis Primers 3:17083

62. Hu L et al (2012) Cell attachment protein VP8* of a human rotavirus specifically interacts with A-type histo-blood group antigen. Nature 485(7397):256-259

63. Lopez S, Arias CF (2004) Multistep entry of rotavirus into cells: a Versaillesque dance. Trends Microbiol 12(6):271-278

64. Arias CF, Silva-Ayala D, Lopez S (2015) Rotavirus entry: a deep journey into the cell with several exits. J Virol 89(2):890-893

65. Gutierrez M et al (2010) Different rotavirus strains enter MA104 cells through different endocytic pathways: the role of clathrinmediated endocytosis. J Virol 84(18):9161-9169

66. Sanchez-San Martin C et al (2004) Characterization of rotavirus cell entry. J Virol 78(5):2310-2318

67. Diaz-Salinas MA et al (2014) Rotaviruses reach late endosomes and require the cation-dependent mannose-6-phosphate receptor and the activity of cathepsin proteases to enter the cell. J Virol 88(8):4389-4402

68. Cohen J et al (1979) Activation of rotavirus RNA polymerase by calcium chelation. Arch Virol 60(3-4):177-186

69. Periz J et al (2013) Rotavirus mRNAS are released by transcriptspecific channels in the double-layered viral capsid. Proc Natl Acad Sci U S A 110(29):12042-12047

70. Long CP, McDonald SM (2017) Rotavirus genome replication: Some assembly required. PLoS Pathog 13(4):e1006242

71. Ding K et al (2019) In situ structures of rotavirus polymerase in action and mechanism of mRNA transcription and release. Nat Commun 10(1):2216

72. Trask SD, McDonald SM, Patton JT (2012) Structural insights into the coupling of virion assembly and rotavirus replication. Nat Rev Microbiol 10(3):165-177

73. Borodavka A et al (2017) Protein-mediated RNA folding governs sequence-specific interactions between rotavirus genome segments. Elife 6:e27453

74. Taylor JA, O'Brien JA, Yeager M (1996) The cytoplasmic tail of NSP4, the endoplasmic reticulum-localized non-structural 
glycoprotein of rotavirus, contains distinct virus binding and coiled coil domains. EMBO J 15(17):4469-4476

75. Trask SD, Dormitzer PR (2006) Assembly of highly infectious rotavirus particles recoated with recombinant outer capsid proteins. J Virol 80(22):11293-11304

76. Trejo-Cerro O et al (2018) Actin-dependent nonlytic rotavirus exit and infectious virus morphogenetic pathway in nonpolarized cells. J Virol 92(6):e02076-e2117

77. Cuadras MA, Greenberg HB (2003) Rotavirus infectious particles use lipid rafts during replication for transport to the cell surface in vitro and in vivo. Virology 313(1):308-321

78. Delmas O et al (2004) Spike protein VP4 assembly with maturing rotavirus requires a postendoplasmic reticulum event in polarized caco-2 cells. J Virol 78(20):10987-10994

79. Altenburg BC, Graham DY, Estes MK (1980) Ultrastructural study of rotavirus replication in cultured cells. J Gen Virol 46(1):75-85

80. Cevallos Porta D et al (2016) Polarized rotavirus entry and release from differentiated small intestinal cells. Virology 499:65-71

81. Isa P et al (2020) Rotaviruses associate with distinct types of extracellular vesicles. Viruses 12(7):763

82. Santiana $M$ et al (2018) Vesicle-cloaked virus clusters are optimal units for inter-organismal viral transmission. Cell Host Microbe 24(2):208-220-e8

83. Gardet A et al (2006) Rotavirus spike protein VP4 binds to and remodels actin bundles of the epithelial brush border into actin bodies. J Virol 80(8):3947-3956

84. Kobayashi T et al (2007) A plasmid-based reverse genetics system for animal double-stranded RNA viruses. Cell Host Microbe 1(2):147-157

85. Richards JE, Desselberger U, Lever AM (2013) Experimental pathways towards developing a rotavirus reverse genetics system: synthetic full length rotavirus ssRNAs are neither infectious nor translated in permissive cells. PLoS ONE 8(9):e74328

86. Navarro A et al (2016) Rotavirus replication and reverse genetics. In: Svensson L et al (eds) Viral gastroenteritis. Academic Press, Boston, pp 121-143

87. Komoto S, Taniguchi K (2013) Genetic engineering of rotaviruses by reverse genetics. Microbiol Immunol 57(7):479-486

88. Fukuda S et al (2020) Rapid generation of rotavirus single-gene reassortants by means of eleven plasmid-only based reverse genetics. J Gen Virol 101(8):806-815

89. Komoto S, Sasaki J, Taniguchi K (2006) Reverse genetics system for introduction of site-specific mutations into the doublestranded RNA genome of infectious rotavirus. Proc Natl Acad Sci USA 103(12):4646-4651

90. Enami M et al (1990) Introduction of site-specific mutations into the genome of influenza virus. Proc Natl Acad Sci U S A 87(10):3802-3805

91. Komoto $\mathrm{S}$ et al (2020) Generation of recombinant rotaviruses from just 11 cDNAs encoding a viral genome. Virus Res 286:198075

92. Conrad T et al (2020) Maximizing transcription of nucleic acids with efficient T7 promoters. Commun Biol 3(1):439

93. Komoto $\mathrm{S}$ et al (2008) Generation of recombinant rotavirus with an antigenic mosaic of cross-reactive neutralization epitopes on VP4. J Virol 82(13):6753-6757

94. Trask SD et al (2010) Dual selection mechanisms drive efficient single-gene reverse genetics for rotavirus. Proc Natl Acad Sci USA 107(43):18652-18657

95. Criglar J et al (2011) Reconciliation of rotavirus temperature-sensitive mutant collections and assignment of reassortment groups $\mathrm{D}, \mathrm{J}$, and K to genome segments. J Virol 85(10):5048-5060
96. Troupin C et al (2010) Rearranged genomic RNA segments offer a new approach to the reverse genetics of rotaviruses. J Virol 84(13):6711-6719

97. Desselberger U (1996) Genome rearrangements of rotaviruses. In: Maramorosch K, Murphy FA, Shatkin AJ (eds) Advances in virus research. Academic Press, pp 69-95

98. Schnepf N et al (2008) Rearrangements of rotavirus genomic segment 11 are generated during acute infection of immunocompetent children and do not occur at random. J Virol 82(7):3689-3696

99. Bellinzoni RC et al (1987) Isolation of group A swine rotaviruses displaying atypical electropherotypes. J Clin Microbiol 25(5):952-954

100. Hundley F et al (1985) Genome rearrangements of bovine rotavirus after serial passage at high multiplicity of infection. Virology 143(1):88-103

101. Kojima K et al (2000) Rearrangement generated in double genes, NSP1 and NSP3, of viable progenies from a human rotavirus strain. Virus Res 67(2):163-171

102. Kobayashi $\mathrm{T}$ et al (2010) An improved reverse genetics system for mammalian orthoreoviruses. Virology 398(2):194-200

103. Johne $\mathrm{R}$ et al (2016) Generation of an avian-mammalian rotavirus reassortant by using a helper virus-dependent reverse genetics system. J Virol 90(3):1439-1443

104. Boyce M, Celma CC, Roy P (2008) Development of reverse genetics systems for bluetongue virus: recovery of infectious virus from synthetic RNA transcripts. J Virol 82(17):8339-8348

105. Boyce M, Roy P (2007) Recovery of infectious bluetongue virus from RNA. J Virol 81(5):2179-2186

106. Duponchel S et al (2014) Transfection of exogenous rotavirus rearranged RNA segments in cells infected with a WT rotavirus results in subsequent gene rearrangements. J Gen Virol 95(Pt 9):2089-2098

107. Kanai Y et al (2017) Entirely plasmid-based reverse genetics system for rotaviruses. Proc Natl Acad Sci USA 114(9):2349-2354

108. Diller JR et al (2019) Rotavirus species B encodes a functional fusion-associated small transmembrane protein. J Virol 93(20):e00813-e819

109. Ciechonska M, Duncan R (2014) Reovirus FAST proteins: virusencoded cellular fusogens. Trends Microbiol 22(12):715-724

110. Brown CW et al (2009) The p14 FAST protein of reptilian reovirus increases vesicular stomatitis virus neuropathogenesis. J Virol 83(2):552-561

111. Komoto $S$ et al (2017) Reverse genetics system demonstrates that rotavirus nonstructural protein NSP6 is not essential for viral replication in cell culture. J Virol 91(21):e00695-e717

112. Komoto $\mathrm{S}$ et al (2018) Generation of recombinant rotaviruses expressing fluorescent proteins by using an optimized reverse genetics system. J Virol 92(13):e00588-e618

113. Komoto $\mathrm{S}$ et al (2019) Generation of infectious recombinant human rotaviruses from just 11 cloned cDNAs encoding the rotavirus genome. J Virol 93(8):e02207-e2218

114. Sanchez-Tacuba L et al (2020) An optimized reverse genetics system suitable for efficient recovery of simian, human, and murine-like rotaviruses. J Virol 94(18):e01294-e1320

115. Jais PH et al (2019) C3P3-G1: first generation of a eukaryotic artificial cytoplasmic expression system. Nucleic Acids Res 47(5):2681-2698

116. Eaton HE et al (2017) African swine fever virus NP868R capping enzyme promotes reovirus rescue during reverse genetics by promoting reovirus protein expression, virion assembly, and RNA incorporation into infectious virions. J Virol 91(11):e02416-e2516

117. Meade $\mathrm{NJ}$ (2016) Intervention strategies against rotavirus in pigs. $\mathrm{PhD}$ Thesis, University of Nottingham, Nottingham, UK 
118. Komoto S et al (2020) Reverse genetics system for human rotaviruses. Microbiol Immunol 64(6):401-406

119. Komoto $\mathrm{S}$ et al (2011) Modification of the trypsin cleavage site of rotavirus VP4 to a furin-sensitive form does not enhance replication efficiency. J Gen Virol 92(Pt 12):2914-2921

120. Schrauwen EJ et al (2012) The multibasic cleavage site in H5N1 virus is critical for systemic spread along the olfactory and hematogenous routes in ferrets. J Virol 86(7):3975-3984

121. Arias CF et al (1996) Trypsin activation pathway of rotavirus infectivity. J Virol 70(9):5832-5839

122. Rodriguez JM et al (2014) New insights into rotavirus entry machinery: stabilization of rotavirus spike conformation is independent of trypsin cleavage. PLoS Pathog 10(5):e1004157

123. Trask SD et al (2013) Mutations in the rotavirus spike protein VP4 reduce trypsin sensitivity but not viral spread. J Gen Virol 94(Pt 6): 1296-1300

124. Menou A et al (2017) Human airway trypsin-like protease, a serine protease involved in respiratory diseases. Am J Physiol Lung Cell Mol Physiol 312(5):L657-L668

125. Antalis TM et al (2010) The cutting edge: membrane-anchored serine protease activities in the pericellular microenvironment. Biochem J 428(3):325-346

126. Straus MR, Whittaker GR (2017) A peptide-based approach to evaluate the adaptability of influenza A virus to humans based on its hemagglutinin proteolytic cleavage site. PLoS ONE 12(3):e0174827

127. Keelapang $\mathrm{P}$ et al (2004) Alterations of pr-M cleavage and virus export in pr-M junction chimeric dengue viruses. J Virol 78(5):2367-2381

128. Crawford SE et al (2001) Trypsin cleavage stabilizes the rotavirus VP4 spike. J Virol 75(13):6052-6061

129. Mattion NM et al (1991) Expression of rotavirus proteins encoded by alternative open reading frames of genome segment 11. Virology 181(1):295-304

130. Rainsford EW, McCrae MA (2007) Characterization of the NSP6 protein product of rotavirus gene 11. Virus Res 130(1-2):193-201

131. Viskovska M et al (2014) Probing the sites of interactions of rotaviral proteins involved in replication. J Virol 88(21):12866-12881

132. Holloway $\mathrm{G}$ et al (2015) Rotavirus NSP6 localizes to mitochondria via a predicted N-terminal a-helix. J Gen Virol 96(12):3519-3524

133. Holloway G, Coulson BS (2013) Innate cellular responses to rotavirus infection. J Gen Virol 94(Pt 6):1151-1160

134. Halasz P, Holloway G, Coulson BS (2010) Death mechanisms in epithelial cells following rotavirus infection, exposure to inactivated rotavirus or genome transfection. J Gen Virol 91(Pt 8):2007-2018

135. Martin-Latil S et al (2007) Bax is activated during rotavirusinduced apoptosis through the mitochondrial pathway. J Virol 81(9):4457-4464

136. Sen A et al (2011) The early interferon response to rotavirus is regulated by PKR and depends on MAVS/IPS-1, RIG-I, MDA5, and IRF3. J Virol 85(8):3717-3732

137. Wu $\mathrm{H}$ et al (1998) Serological and genomic characterization of human rotaviruses detected in China. J Med Virol 55(2):168-176

138. Gonzalez SA, Burrone OR (1989) Porcine OSU rotavirus segment II sequence shows common features with the viral gene of human origin. Nucleic Acids Res 17(15):6402

139. Graff JW, Ettayebi K, Hardy ME (2009) Rotavirus NSP1 inhibits NFkappaB activation by inducing proteasome-dependent degradation of beta-TrCP: a novel mechanism of IFN antagonism. PLoS Pathog 5(1):e1000280
140. Bagchi $P$ et al (2010) Rotavirus nonstructural protein 1 suppresses virus-induced cellular apoptosis to facilitate viral growth by activating the cell survival pathways during early stages of infection. J Virol 84(13):6834-6845

141. Barro M, Patton JT (2005) Rotavirus nonstructural protein 1 subverts innate immune response by inducing degradation of IFN regulatory factor 3. Proc Natl Acad Sci USA 102(11):4114-4119

142. Papa G et al (2019) Recombinant rotaviruses rescued by reverse genetics reveal the role of NSP5 hyperphosphorylation in the assembly of viral factories. J Virol 94(1):e01110-e1119

143. Song Y et al (2020) Reverse genetics reveals a role of rotavirus vp3 phosphodiesterase activity in inhibiting rnase 1 signaling and contributing to intestinal viral replication in vivo. J Virol 94(9):e01952-e2019

144. Mohanty SK et al (2017) A point mutation in the rhesus rotavirus vp4 protein generated through a rotavirus reverse genetics system attenuates biliary atresia in the murine model. J Virol 91(15):e00510-e517

145. Mohanty SK et al (2017) The SRL peptide of rhesus rotavirus VP4 protein governs cholangiocyte infection and the murine model of biliary atresia. Hepatology 65(4):1278-1292

146. Criglar JM et al (2020) A genetically engineered rotavirus nsp2 phosphorylation mutant impaired in viroplasm formation and replication shows an early interaction between vNSP2 and cellular lipid droplets. J Virol 94(15):e00972-e1020

147. Falkenhagen A et al (2021) Rescue of infectious rotavirus reassortants by a reverse genetics system is restricted by the receptor-binding region of VP4. Viruses 13(3):363

148. Kanai $Y$ et al (2019) Development of stable rotavirus reporter expression systems. J Virol 93(4):e01774-e1818

149. Kanai $Y$ et al (2020) Reverse genetics approach for developing rotavirus vaccine candidates carrying VP4 and VP7 Genes cloned from clinical isolates of human rotavirus. J Virol 95(2):e01374-e1420

150. McIntyre $\mathrm{M}$ et al (1987) Biophysical characterization of rotavirus particles containing rearranged genomes. J Gen Virol 68 (Pt 11)(11):2961-2966

151. Ozawa $M$ et al (2011) Replication-incompetent influenza A viruses that stably express a foreign gene. J Gen Virol 92(Pt 12):2879-2888

152. Desselberger U (2020) Potential of plasmid only based reverse genetics of rotavirus for the development of next-generation vaccines. Curr Opin Virol 44:1-6

153. McDonald SM, Patton JT (2011) Assortment and packaging of the segmented rotavirus genome. Trends Microbiol 19(3): 136-144

154. Suzuki Y (2014) A possible packaging signal in the rotavirus genome. Genes Genet Syst 89(2):81-86

155. Hua J, Patton JT (1994) The carboxyl-half of the rotavirus nonstructural protein NS53 (NSP1) is not required for virus replication. Virology 198(2):567-576

156. Taniguchi K, Kojima K, Urasawa S (1996) Nondefective rotavirus mutants with an NSP1 gene which has a deletion of 500 nucleotides, including a cysteine-rich zinc finger motif-encoding region (nucleotides 156 to 248), or which has a nonsense codon at nucleotides 153-155. J Virol 70(6):4125-4130

157. Patton JT et al (2001) Effect of intragenic rearrangement and changes in the 3' consensus sequence on NSP1 expression and rotavirus replication. J Virol 75(5):2076-2086

158. Philip AA et al (2019) Collection of recombinant rotaviruses expressing fluorescent reporter proteins. Microbiol Resour Announc 8(27):e00523-e619

159. Philip AA et al (2020) Simplified reverse genetics method to recover recombinant rotaviruses expressing reporter proteins. J Vis Exp 158:e61039 
160. Chang-Graham AL et al (2019) rotavirus calcium dysregulation manifests as dynamic calcium signaling in the cytoplasm and endoplasmic reticulum. Sci Rep 9(1):10822

161. Navarro A, Trask SD, Patton JT (2013) Generation of genetically stable recombinant rotaviruses containing novel genome rearrangements and heterologous sequences by reverse genetics. J Virol 87(11):6211-6220

162. Zhang $X$ et al (2015) In situ structures of the segmented genome and RNA polymerase complex inside a dsRNA virus. Nature 527(7579):531-534

163. Philip AA, Patton JT (2020) Expression of separate heterologous proteins from the Rotavirus NSP3 genome segment using a translational 2A stop-restart element. J Virol 94(18):e00959-00920

164. Philip AA et al (2019) Generation of recombinant rotavirus expressing NSP3-UnaG fusion protein by a simplified reverse genetics system. J Virol 93(24):e01616-e1619

165. Komoto $S$ et al (2016) Reassortment of Human and Animal Rotavirus Gene Segments in Emerging DS-1-Like G1P[8] Rotavirus Strains. PLoS ONE 11(2):e0148416

166. Leite JP et al (1996) Rotavirus G and P types circulating in Brazil: characterization by RT-PCR, probe hybridization, and sequence analysis. Arch Virol 141(12):2365-2374

167. Palombo EA (2002) Genetic analysis of Group A rotaviruses: evidence for interspecies transmission of rotavirus genes. Virus Genes 24(1):11-20

168. Li W et al (2010) Genomic analysis of codon, sequence and structural conservation with selective biochemical-structure mapping reveals highly conserved and dynamic structures in rotavirus RNAs with potential cis-acting functions. Nucleic Acids Res 38(21):7718-7735

169. Fajardo T Jr et al (2017) Rotavirus genomic RNA complex forms via specific RNA-RNA interactions: disruption of rna complex inhibits virus infectivity. Viruses 9(7):167

170. Mingo R et al (2017) Genetic determinants restricting the reassortment of heterologous NSP2 genes into the simian rotavirus SA11 genome. Sci Rep 7(1):9301

171. Falkenhagen A et al (2019) Generation of simian rotavirus reassortants with diverse VP4 genes using reverse genetics. J Gen Virol 100(12):1595-1604

172. Patzina-Mehling $\mathrm{C}$ et al (2020) Potential of avian and mammalian species A rotaviruses to reassort as explored by plasmid onlybased reverse genetics. Virus Res 286:e198027

173. Falkenhagen A et al (2020) Generation of simian rotavirus reassortants with VP4- and VP7-encoding genome segments from human strains circulating in Africa using reverse genetics. Viruses 12(2):201

174. Burnett $\mathrm{E}$ et al (2017) Global impact of rotavirus vaccination on childhood hospitalizations and mortality from diarrhea. J Infect Dis 215(11):1666-1672

175. Aliabadi N et al (2019) Global impact of rotavirus vaccine introduction on rotavirus hospitalisations among children under 5 years of age, 2008-16: findings from the Global Rotavirus Surveillance Network. Lancet Glob Health 7(7):e893-e903

176. Burke RM et al (2019) Current and new rotavirus vaccines. Curr Opin Infect Dis 32(5):435-444

177. Soares-Weiser K et al (2019) Vaccines for preventing rotavirus diarrhoea: vaccines in use. Cochrane Database Syst Rev. https:// doi.org/10.1002/14651858.CD008521.pub5

178. Parker EP et al (2018) Causes of impaired oral vaccine efficacy in developing countries. Future Microbiol 13(1):97-118

179. Desselberger U (2017) Differences of rotavirus vaccine effectiveness by country: likely causes and contributing factors. Pathogens 6(4):65

180. Clark A et al (2019) Mortality reduction benefits and intussusception risks of rotavirus vaccination in 135 low-income and middle-income countries: a modelling analysis of current and alternative schedules. Lancet Glob Health 7(11):e1541-e1552

181. Velasquez DE, Parashar U, Jiang B (2018) Decreased performance of live attenuated, oral rotavirus vaccines in low-income settings: causes and contributing factors. Expert Rev Vaccines 17(2):145-161

182. Weintraub ES et al (2014) Risk of intussusception after monovalent rotavirus vaccination. N Engl J Med 370(6):513-519

183. Fu C et al (2018) Rotavirus gastroenteritis infection among children vaccinated and unvaccinated with rotavirus vaccine in Southern China: a population-based assessment. JAMA Netw Open 1(4):e1813382

184. Bines JE et al (2018) Human neonatal rotavirus vaccine (RV3BB) to target rotavirus from birth. N Engl J Med 378(8):719-730

185. Velazquez FR et al (1996) Rotavirus infection in infants as protection against subsequent infections. N Engl J Med 335(14):1022-1028

186. Desselberger U, Huppertz HI (2011) Immune responses to rotavirus infection and vaccination and associated correlates of protection. J Infect Dis 203(2):188-195

187. Nair N et al (2017) VP4- and VP7-specific antibodies mediate heterotypic immunity to rotavirus in humans. Sci Transl Med 9(395):eaam5434

188. Burns JW et al (1996) Protective effect of rotavirus VP6-specific IgA monoclonal antibodies that lack neutralizing activity. Science 272(5258): 104-107

189. Gorrell RJ, Bishop RF (1999) Homotypic and heterotypic serum neutralizing antibody response to rotavirus proteins following natural primary infection and reinfection in children. J Med Virol 57(2):204-211

190. Caddy SL et al (2020) Intracellular neutralisation of rotavirus by VP6-specific IgG. PLoS Pathog 16(8):e1008732

191. Kirkwood CD (2010) Genetic and antigenic diversity of human rotaviruses: potential impact on vaccination programs. J Infect Dis 202 Suppl(S1):S43-S48

192. Ramakrishnan G et al (2019) Rotavirus vaccine protection in low-income and middle-income countries. Lancet Infect Dis 19(7):673-674

193. Murphy TV et al (2001) Intussusception among infants given an oral rotavirus vaccine. N Engl J Med 344(8):564-572

194. Kirkwood CD et al (2019) The rotavirus vaccine development pipeline. Vaccine 37(50):7328-7335

195. Stobart CC, Moore ML (2014) RNA virus reverse genetics and vaccine design. Viruses 6(7):2531-2550

196. Uchida Y, Takemae N, Saito T (2014) Application of reverse genetics for producing attenuated vaccine strains against highly pathogenic avian influenza viruses. J Vet Med Sci 76(8):1111-1117

197. Lopman BA et al (2016) The Vast and Varied Global Burden of Norovirus: Prospects for Prevention and Control. PLoS Med 13(4):e1001999

198. Philip AA, Patton JT (2021) Rotavirus as an expression platform of domains of the SARS-CoV-2 spike protein. Vaccines 9(5):449

199. Philip AA et al (2020) Rotaviruses as neonatal vaccine expression vectors against other enteric pathogens. Processdings 50(1):53

200. Papp H et al (2014) Rotavirus strains in neglected animal species including lambs, goats and camelids. Virusdisease 25(2):215-222

201. Luchs A, Timenetsky MDOC (2016) rotavirus gastroenteritis: post-vaccine era, genotypes and zoonotic transmission. Einstein (Sao Paulo) 14(2):278-287

202. Ghosh S, Kobayashi N (2014) Exotic rotaviruses in animals and rotaviruses in exotic animals. Virusdisease 25(2):158-172 
203. Collins PJ, Martella V, O'Shea H (2008) Detection and characterization of group $\mathrm{C}$ rotaviruses in asymptomatic piglets in Ireland. J Clin Microbiol 46(9):2973-2979

204. Chinsangaram J et al (1995) Prevalence of group A and group B rotaviruses in the feces of neonatal dairy calves from California. Comp Immunol Microbiol Infect Dis 18(2):93-103

205. Almeida PR et al (2018) Diarrhea caused by rotavirus A, B, and $\mathrm{C}$ in suckling piglets from southern Brazil: molecular detection and histologic and immunohistochemical characterization. J Vet Diagn Invest 30(3):370-376

206. Vlasova AN, Amimo JO, Saif LJ (2017) Porcine rotaviruses: epidemiology, immune responses and control strategies. Viruses 9(3):48
207. Hull JJA et al (2020) Metagenomic sequencing generates the whole genomes of porcine rotavirus $\mathrm{A}, \mathrm{C}$, and $\mathrm{H}$ from the United States. PLoS ONE 15(12):e0244498

208. Saif LJ, Fernandez FM (1996) Group A rotavirus veterinary vaccines. J Infect Dis 174 Suppl 1(Suppl 1):S98-106

209. Tacharoenmuang $R$ et al (2018) Characterization of a G10P[14] rotavirus strain from a diarrheic child in Thailand: Evidence for bovine-to-human zoonotic transmission. Infect Genet Evol 63:43-57

Publisher's Note Springer Nature remains neutral with regard to jurisdictional claims in published maps and institutional affiliations. 